\title{
Inhibition of Hypercholesterolemia-induced Atherosclerosis in the Nonhuman Primate by Probucol
}

\author{
I. Is the Extent of Atherosclerosis Related to Resistance of LDL to Oxidation?
}

\author{
Masakiyo Sasahara, * Elaine W. Raines, * Alan Chait, ${ }^{*}$ Thomas E. Carew, \\ Russell Ross* \\ Departments of * Pathology, ${ }^{\ddagger}$ Medicine, and ${ }^{8}$ Biostatistics, University of Washington, Seattle, Washington 98195; and "Department of \\ Medicine, University of California, San Diego, La Jolla, California 92093
}

\section{Abstract}

Lipoprotein oxidation is believed to play an important role in atherogenesis. To investigate whether inhibition of oxidation of low density lipoprotein (LDL) would alter atherogenesis in the nonhuman primate, we administered probucol, a potent antioxidant, to Macaca nemestrina fed a high-fat, high-cholesterol diet. Probucol was administered to half of the 16 monkeys 14 wk after starting the hypercholesterolemic diet, and was given daily until they were sacrificed after 11 mos. To evaluate the antioxidant effect of probucol, the resistance of isolated plasma LDL to in vitro oxidation was evaluated. Probucol significantly increased the resistance of LDL to oxidative modification, as shown by an increase in the lag time required for conjugated diene formation. Lesions in the probucol-treated animals appeared less mature, and increased accumulation of lipid was observed in smooth muscle cells. Comparison of all control and probucol-treated monkeys demonstrated that intimal lesion areas in the thoracic aortas of the probucol-treated monkeys were reduced by $43 \%(P<0.0001)$, but no significant difference in lesion area was found in the abdominal aortas or in the iliac arteries. However, the lag phase of conjugated diene formation was not prolonged in 2 of the 8 probucol-treated animals. A plot of intimal lesion size versus lag phase of all 16 animals showed a trend that lesion size was inversely related to oxidation resistance for all anatomic sites. The strong inverse relationship between intimal lesion size and resistance of LDL to oxidation supports a role for lipoprotein oxidation in the development and progression of lesions of atherosclerosis. The possibility that some of the effect is due to other biological properties of probucol cannot be ruled out. (J. Clin. Invest. 1994. 94:155-164.) Key words: low density lipoprotein - antioxidant • lesions of atherosclerosis • cholesterol • oxidized LDL

\footnotetext{
${ }^{\dagger}$ Dr. Carew died on 7 May 1993. We dedicate this paper to the memory of a brilliant and beloved colleague.

Address correspondence to Russell Ross, Department of Pathology, SM30, University of Washington School of Medicine, Seattle, WA 98195.

Received for publication 18 August 1993 and in revised form 24 February 1994.
}

J. Clin. Invest.

(C) The American Society for Clinical Investigation, Inc.

0021-9738/94/07/0155/10 \$2.00

Volume 94, July 1994, 155-164

\section{Introduction}

Atherogenesis has long been accepted as the pathologic process that leads to occlusive arterial lesions principally responsible for myocardial and cerebral infarction, gangrene of the extremities, and subsequent loss of function. An hypothesis $(1,2)$ based upon earlier observations $(3,4)$ has been developed which proposes that the lesions of atherosclerosis result from the response of the arterial wall cells to numerous forms of injury. This specialized chronic inflammatory, fibroproliferative response is generally considered to be protective against injury. However, when the response to injury is chronically excessive, it can become the disease, atherosclerosis. One form of injury to arterial cells results from excessive levels of circulating low density lipoprotein (LDL) cholesterol. The role of chronic hypercholesterolemia in atherogenesis has received widespread attention because of the epidemiologic association of hypercholesterolemia with atherosclerosis and the many studies showing that decreases in plasma LDL cholesterol can lead to lesion regression and reduction of clinical coronary artery occlusive events (5).

Studies of lipoprotein-cell interactions are beginning to provide insight into mechanisms by which hypercholesterolemia may initiate arterial injury. A growing body of evidence indicates that LDL must undergo some modification of structure before it becomes atherogenic. This was first suggested by Brown and Goldstein (6), who showed that uptake of native LDL by macrophages would not generate foam cells but that uptake of chemically acetylated LDL would. The uptake occurred via a specific, saturable receptor which has been cloned (7). Henriksen et al. (8) showed that incubation of LDL with endothelial cells in culture could modify LDL to a form recognized by the acetyl LDL receptor, and that this modification was determined to be oxidative in nature $(9,10)$. LDL can be oxidized via free radical mechanisms by endothelial cells, smooth muscle cells, and monocyte/macrophages (9-11). Oxidized LDL has a number of biological effects that may contribute to atherosclerosis, including cytotoxicity, induction of specific genes in endothelial cells, suppression of growth factor and cytokine gene expression, promotion of procoagulant activity, and immunogenicity $(12,13)$. A key role for LDL oxidation in atherogenesis was demonstrated in studies with probucol, a powerful antioxidant (14), in which the development of arterial lesions in the LDL receptor-deficient rabbit was reduced by $50-$ $80 \%(15,16)$. However, except for its use as a lipid-lowering agent (17), there has been only one study of antioxidant therapy in nonhuman primates (18). The remaining studies of the effectiveness of antioxidants in atherogenesis have been carried out in rabbits $(15,16,19-22)$. 
The present investigation was designed to ask whether administration of probucol as an antioxidant altered the process of atherogenesis in the hypercholesterolemic nonhuman primate Macaca nemestrina, an animal that more closely approximates the human disease. Administration of the high-fat, high-cholesterol diet to produce plasma cholesterol levels of $600-700 \mathrm{mg} /$ dl for 3 mos has previously been shown to induce lesions of atherosclerosis ranging from early fatty streaks in the thoracic aorta to intermediate, fibrofatty lesions in the iliac arteries (23). These early studies demonstrated mural thrombi over fibrofatty lesions resulting from platelet adherence to exposed foam cells after 4 mos on the diet. Endothelial retraction over fibrofatty lesions with increased connective tissue was observed in $30 \%$ of the segments of the iliac arteries. Advanced fibrous plaques were first observed at similar anatomic sites in animals maintained at the same plasma cholesterol levels for 5-13 mos. The level and duration of hypercholesterolemia of these monkeys have consistently correlated with the stage of lesion development at specific anatomic sites (24-26).

In the present study, probucol was administered to half of the animals after they had been on a hypercholesterolemic diet for three and one-half months. The ability of probucol to alter progression of the lesions present at the time probucol administration was initiated (very early lesions in the thoracic aorta and more advanced, fibrofatty lesions in the abdominal aorta and iliac arteries) was evaluated after 11 mos on the hypercholesterolemic diet. At the time of sacrifice, extensive advanced lesions are normally present throughout the arterial tree, including the thoracic aorta. Quantitation of intimal lesion area demonstrated a significant reduction in the thoracic aorta of probucol-treated animals and a trend to smaller lesions at all sites as the resistance of plasma LDL to oxidation increased. This study in the nonhuman primate provides further support for the possible use of antioxidants in the prevention and treatment of atherosclerosis.

\section{Methods}

Animals. A total of 46 male pigtail monkeys (M. nemestrina), 3-5 yr of age (average weight 4-7 kg), were fed an atherogenic diet containing $0.5 \%$ cholesterol and maintained on the diet for 3.5 mos. Groups of 8 14 animals were screened at a time. 22 animals, who responded to the diet with persistent plasma cholesterol levels of between 500 and 700 $\mathrm{mg} / \mathrm{dl}$, were selected from the 46 animals for further study. This selection was performed to provide more comparable groups of animals and is based on prior studies, where a strong correlation was demonstrated between the level and duration of hypercholesterolemia with both site and severity of lesion formation (23-26). Animals excluded from the study were not evaluated further. The 22 animals selected by this screening were continued on the atherogenic diet for an additional $7.5 \mathrm{mos}$, during which time one half of the animals received probucol and the other half received only the carrier, methylcellulose, which was used to administer the probucol. Probucol $(60 \mathrm{mg} / \mathrm{kg}$; suspended and homogenized in $0.25 \%$ methylcellulose in water at $240 \mathrm{mg} / \mathrm{ml})$ or carrier $(0.25 \%$ methylcellulose in water) was mixed with three parts apple juice and administered between 8:00 and 9:00 AM daily. No food was available to the animals at the time of administration of the probucol or carrier, and the animals were not fed until $7.5 \mathrm{~h}$ after being given probucol. Probucol was administered separately from the diet to prevent cardiotoxicity previously observed with simultaneous administration of the drug and food (27). After 11 mos on the diet, eight animals from each group were sacrificed to quantitate intimal lesion area, and the arteries of the remaining three animals from each group were perfused with fixative prior to removal to evaluate lesion morphology. Procedures conformed to the Guide for Care and Use of Laboratory Animals, issued by the U.S. Institute of Laboratory Resources.

Blood samples. Each animal was bled bimonthly during the experimental period to monitor the changes in plasma cholesterol and probucol levels. In addition, blood samples were drawn once or twice (twice each for four probucol-treated and four control animals used for the intimal area quantitation studies and once each for the remaining seven animals in each group) during the probucol treatment for isolation of LDL and measurement of its resistance to oxidative modification, as described below. Repeat measurements of diene lag times made at separate times on the same animals varied by $<4 \%$. Cholesterol, triglyceride, and probucol levels were determined for all blood samples. Lipoprotein concentrations were determined a minimum of three times during the experimental period, once before and twice after the administration of probucol or carrier. Lipoprotein analyses were performed by the Northwest Lipid Research Laboratory using standard established procedures (28). Probucol levels were determined by high performance liquid chromatography by Wisconsin Analytical and Research Services, Ltd. (Madison, WI).

Diet. The atherogenic diet mixture used in this study was identical to that used in our previous studies of hypercholesterolemia-induced atherosclerosis in $M$. nemestrina $(23,24)$. The diet mixture provided $42 \%$ of its calories from fat and was supplemented with cholesterol for a total concentration of $0.5 \mathrm{~g}$ of cholesterol for every $100 \mathrm{~g}$ of diet $(0.5 \%)$. Since probucol is known to lower plasma cholesterol levels, the animals that were to serve as controls were started on the diet 4 mos after the probucol-treated animals. This was accomplished by screening groups of 8-14 animals each and staggering the initiation of screening by 4 mos. The diet of the control animals was adjusted from time to time, as required, by mixing the atherogenic diet with normal chow (0.25-0.5\% cholesterol content for all control animals) to match the plasma cholesterol levels of the probucol-treated animals. The plasma cholesterol levels in the 11 probucol-treated animals decreased $22 \% \pm 17$; the level in the control animals had a mean decrease of $32 \% \pm 7$. The pair-fed animals lagged behind the experimental group by 4 mos, including the time of sacrifice. Each monkey was housed in a single cage and fed daily ad libitum. Dietary intake was monitored, and bimonthly determinations were made of body weight.

Isolation of $L D L$ and measurement of its resistance to oxidative modification. Plasma was separated within one hour of collection, and LDL $(d=1.019-1.063 \mathrm{~g} / \mathrm{ml})$ was isolated by the rapid single spin vertical ultracentrifugal method described by Chung et al. (29). Briefly, a discontinuous $\mathrm{NaCl} / \mathrm{KBr}$ density gradient was formed by adjusting the density of the plasma to $1.30 \mathrm{~g} / \mathrm{ml}$ with $\mathrm{KBr}$ and layering normal saline $(d=1.006 \mathrm{~g} / \mathrm{ml})$ over the plasma. Tubes were placed in a Beckman VTI-50 ultracentrifuge rotor and centrifuged for $2.5 \mathrm{~h}$ at $50,000 \mathrm{rpm}$ at $10^{\circ} \mathrm{C}$ (Beckman Instruments, Inc., Fullerton, CA). The LDL band, which is separated from HDL by a large, clear area, was located by inspection, and the tube was sliced to remove the LDL band. The LDL was rapidly desalted over a Sephadex G-300 column. The G300 column completely separates LDL from albumin by using ${ }^{125} \mathrm{I}-$ albumin as an internal control (data not shown). The cholesterol content of the LDL fractions was measured using a Boehringer Mannheim cholesterol assay kit (Boehringer Mannheim Corp., Indianapolis, IN), and all samples were diluted in normal saline to give a final concentration of $300 \mu \mathrm{g} / \mathrm{ml}$ cholesterol for the oxidation studies. There was a 4-6-h delay from the time of collection of the blood samples to the initiation of the oxidation studies. However, the samples remained in the presence of EDTA throughout this period, except for the last stage when the EDTA was removed by passage over the Sephadex G-300 column.

Measurement of the resistance of LDL to oxidative modification was performed as described by Esterbauer et al. (30). Oxidation was initiated by addition of freshly prepared $\mathrm{CuSO}_{4}$ (final concentration of $1.66 \mu \mathrm{M}$ ) to samples containing $300 \mu \mathrm{g} / \mathrm{ml}$ cholesterol in a final volume of $1 \mathrm{ml}$. The kinetic parameters of the oxidation of LDL were determined by monitoring the change in absorbance at $234 \mathrm{~nm}$ at $37^{\circ} \mathrm{C}$ on a Beckman 
Model DU-70 spectrophotometer (Beckman Instruments, Inc.) equipped with a 6-position automatic sample changer. The absorbance curves of 6 LDL specimens ( 3 probucol, 3 control) were determined in parallel. The initial absorbance at $234 \mathrm{~nm}$ was set to 0 , and the increase in absorbance was then recorded every $5 \mathrm{~min}$ for $16 \mathrm{~h}$. The change in absorbance at 234 versus time was divided into three consecutive phases: a lag phase, a propagation phase, and a decomposition phase. The lag time was defined as the number of minutes between time zero and the intercept of the tangent of the slope of the curve with the time-scale axis.

Isolation and radiolabeling of $L D L$. Approximately $20 \mathrm{ml}$ of blood from four control and four probucol-treated monkeys was collected under sterile conditions into $0.4 \mathrm{ml}$ EDTA stock solution $(50 \mathrm{mg} / \mathrm{ml}$ disodium EDTA in water) and $100 \mu$ l protease inhibitor stock solution ( $0.4 \mathrm{M}$ benzamidine, $0.2 \mathrm{mM}$ PPACK). After separation of the blood cells by low speed centrifugation, antibiotic stock solution was added to the plasma (gentamicin, $100 \mu \mathrm{g} / \mathrm{ml}$ final concentration). The plasmas of the four animals in each group were pooled. LDL was prepared from each of the pooled plasma samples $(1.020<d<1.063 \mathrm{~g} / \mathrm{ml})$ by sequential ultracentrifugation (31). After extensive dialysis in PBSEDTA ( $0.15 \mathrm{M} \mathrm{NaCl}, 20 \mathrm{mM}$ Na phosphate, $2 \mathrm{mM}$ EDTA), the LDL preparations were labeled directly in the protein moiety with ${ }^{125} \mathrm{I}$ and coupled with ${ }^{131} \mathrm{I}$-tyramine cellobiose $\left({ }^{131} \mathrm{I}\right.$-TC), as previously described (15) except that in the earlier studies the two isotopic forms of iodine were reversed. After dialysis against PBS-EDTA over $48 \mathrm{~h}$, the specific activities of the preparations were $\sim 100 \mathrm{cpm} / \mu \mathrm{g}$ protein for ${ }^{125} \mathrm{I}$ and $50 \mathrm{cpm} / \mu \mathrm{g}$ protein for ${ }^{131} \mathrm{I}$-TC. $<1 \%$ of the radioactivity stayed in the form of free iodide, and $<2 \%$ was extractable into lipid solvents.

LDL metabolism studies. In four of the control and four of the probucol-treated monkeys also used for quantitation of lesion area (see Table II), $1 \mathrm{ml}$ of double-labeled LDL $\left(\sim 9 \times 10^{8} \mathrm{cpm}{ }^{125} \mathrm{I}\right.$ and 4 $\times 10^{8} \mathrm{cpm}{ }^{131} \mathrm{I}$ ) was injected via the antecubital vein. The animals were tranquilized for the initial injections and blood draws. Eight blood samples were obtained at intervals over the 92-94 h before sacrifice: $10 \mathrm{~min}, 30 \mathrm{~min}$, and $1 \mathrm{~h}$ after injection, two samples on the day after injection, and daily samples for the remaining $3 \mathrm{~d}$. After sacrifice, the descending thoracic and abdominal aortas were divided into six specimens each, and the right and left iliac arteries were divided longitudinally into two specimens each. One half of each specimen was prepared for histologic examination; radioactivity was determined in the other half. The specimens were weighed and radioassayed in a gamma scintillation counter. Protein-bound radioactivity in plasma was determined as that precipitable in $10 \%$ trichloroacetic acid.

The plasma fractional catabolic rate of LDL, an index of the whole body rate of plasma LDL degradation, and arterial tissue fractional catabolic rates were calculated from the radioactivity data as previously described (32). The principles underlying the use of nondegradable tyramine cellobiose coupled to protein to determine the tissue sites and rates of catabolism of plasma proteins or lipoproteins have been described by Pittman and Co-workers $(33,34)$.

Animal sacrifice and perfusion fixation. The 11 monkeys in each group were further divided into two groups: for histologic examination only (three each from control and probucol-treated animals) (Table III), or for quantitation of lesion area (eight each from control and probucol groups). For the animals whose tissues were used for quantitation of lesion area, the thoracic and abdominal aortas and iliac arteries were rapidly removed after ketamine anesthesia and a lethal injection of phenobarbital. The vessels were cut open longitudinally, washed well with sterile PBS, and cut into 16 segments: six for the thoracic aorta, six for the abdominal aorta, and two each for the left and right iliac arteries, as previously described $(23,25,26)$. Identical segments were taken from each animal using the distance from branch points as an internal reference.

Tissue used for morphometric analysis from each of these segments was immediately immersion fixed in methyl Carnoy's fixative $(60 \%$ methanol, $30 \%$ chloroform, $10 \%$ acetic acid) containing butylated hy- droxytoluene (BHT, $25 \mu \mathrm{M}$ ) overnight, dehydrated through a graded series of methanol, and embedded in paraffin.

Animals whose arteries were prepared for histologic examination were perfused under arterial pressure before removal. Both femoral veins were exposed and cannulated for perfusion runoff in animals anesthetized intramuscularly with ketamine. A cannula connected to a perfusion apparatus was inserted into the right carotid artery. Just before exsanguination, each animal was given an intravenous bolus injection of sodium pentobarbital, and the blood was flushed with lactated Ringer's solution at a flow rate of $400 \mathrm{ml} / \mathrm{min}$, which was required to maintain an intraarterial pressure of $90-110 \mathrm{~mm}$ Mercury. When the runoff was clear, 2-4 liters of $2.5 \%$ glutaraldehyde in $0.1 \mathrm{M}$ phosphate buffer was pumped at the same flow rate. After perfusion, the femoral veins and the cannulated carotid artery were clamped, and the arteries were fixed under pressure for an additional $30 \mathrm{~min}$. After perfusion fixation, the thoracic and abdominal aortas and iliac arteries were dissected from each animal. The arteries were cleaned of surrounding connective tissue and the aorta and iliac arteries were also cut into 16 segments as described above. Each segment was further divided into two parts: a 2$\mathrm{mm}$ section was taken for light microscopic and transmission electron microscopic examination, and the remaining larger portion was processed for scanning electron microscopy. All of the samples were immersion fixed in glutaraldehyde overnight at $4^{\circ} \mathrm{C}$. After fixation, each 2-mm section of artery was washed thoroughly in $0.1 \mathrm{M}$ phosphate buffer and was postfixed in $0.1 \%$ osmium tetroxide buffered with 0.1 $\mathrm{M}$ phosphate buffer for $3 \mathrm{~h}$ at room temperature. The samples were then immersed in $50 \%$ ethanol for $15 \mathrm{~min}$, followed by $1 \mathrm{~h}$ in $70 \%$ ethanol containing 3\% uranyl acetate. Dehydration was completed by using a graded series of increasing concentrations of ethanol followed by propylene oxide. Each sample was then embedded in Medcast (Ted Pella, Inc., Redding, CA). Three 1- $\mu \mathrm{m}$ sections were cut from each embedded ring and were stained with basic fuchsin-methylene blue. The slides were examined and photographed with a Nikon photomicroscope.

Measurement of intimal areas. Transverse sections were prepared from each of the 16 segments of vessel from eight probucol-treated and eight control animals and stained for elastin. Identical anatomic segments were taken from control and probucol-treated animals using the distance from reference branch points to evaluate the same regions of the thoracic and abdominal aortas and iliac arteries. The entire area of the intimal lesion on each section was determined using an image analysis system interfaced with an Olympus BH-2 light microscope (Optimas Software, Bioscan, Edmonds, WA). The intimal area was measured by tracing the luminal surface and internal elastic lamina of the aortic segment on the computer image of each lesion using a $10 \times$ objective lens. Medial area was also measured and both intimal and medial areas were expressed as unit area.

Statistical methods. Arterial tissue LDL catabolic rates in probucoltreated and control animals (four animals from each group) were examined by analysis of variance (ANOVA) using a BMDP Statistical Software program (Los Angeles, CA). Statistical analyses were performed on intima values from three measurement sites (thoracic, abdominal, iliac) on 16 monkeys. For each monkey, the thoracic and abdominal values are the mean of six serial sections from identical segments, and the iliac value is the mean of 4 . Body weights are the mean of measurements taken at $\mathbf{1 5}$ different times. Each monkey has a lipid profile determined $30 \mathrm{wk}$ after initiation of diet consisting of cholesterol $(\mathrm{CH})$, triglycerides (TG), very low density lipoprotein (VLDL), LDL, high density lipoprotein (HDL), $\mathrm{HDL}_{2}, \mathrm{HDL}_{3}$, and a cholesterol measurement corresponding to the same time that diene lag time was measured. 15 monkeys also have a TG measurement corresponding to the diene measurement.

Several intimal areas, lipid levels, and probucol values have positively skewed distributions and were transformed for particular analyses, using either square root or logarithmic transformations, to approximate normality. Whenever possible, because of the small number of observations ( $n \leq 16)$, in addition to the mean and standard deviation, statistics based on rank values were used (35); e.g., medians, Wilcoxon rank 
Table I. Comparison of Lipoprotein Profiles of Probucol-treated and Control Animals

\begin{tabular}{|c|c|c|c|c|}
\hline Variable & & Control & Probucol & $P$ value \\
\hline $\mathbf{N}$ & & 8 & 8 & \\
\hline \multirow[t]{5}{*}{ Cholesterol (mg/dl) } & Mean & 612 & 625 & .834 \\
\hline & Median & 628 & 626 & \\
\hline & Minimum & 449 & 285 & \\
\hline & Maximum & 743 & 909 & \\
\hline & SD & 102 & 198 & \\
\hline \multirow[t]{5}{*}{ TG (mg/dl) } & Mean & 11.20 & 15.30 & .156 \\
\hline & Median & 7.50 & 16.00 & \\
\hline & Minimum & 5.00 & 5.00 & \\
\hline & Maximum & 30.50 & 25.00 & \\
\hline & SD & 8.78 & 6.55 & \\
\hline \multirow[t]{5}{*}{ VLDL (mg/dl) } & Mean & 36.2 & 32.2 & .100 \\
\hline & Median & 24.7 & 33.5 & \\
\hline & Minimum & 5.0 & 6.5 & \\
\hline & Maximum & 91.5 & 71.0 & \\
\hline & SD & 32.4 & 21.7 & \\
\hline \multirow[t]{5}{*}{ LDL (mg/dl) } & Mean & 533 & 545 & .834 \\
\hline & Median & 548 & 588 & \\
\hline & Minimum & 252 & 92 & \\
\hline & Maximum & 737 & 797 & \\
\hline & SD & 159 & 226 & \\
\hline \multirow[t]{5}{*}{ HDL (mg/dl) } & Mean & 38.20 & 32.60 & .318 \\
\hline & Median & 36.00 & 28.80 & \\
\hline & Minimum & 21.30 & 23.00 & \\
\hline & Maximum & 63.00 & 47.50 & \\
\hline & SD & 13.50 & 8.85 & \\
\hline \multirow[t]{5}{*}{$\mathrm{HDL}_{2}(\mathrm{mg} / \mathrm{dl})$} & Mean & 11.30 & 6.88 & .040 \\
\hline & Median & 9.00 & 4.50 & \\
\hline & Minimum & 5.30 & 3.00 & \\
\hline & Maximum & 27.00 & 20.50 & \\
\hline & SD & 7.25 & 5.72 & \\
\hline \multirow[t]{5}{*}{$\mathrm{HDL}_{3}(\mathrm{mg} / \mathrm{dl})$} & Mean & 26.00 & 25.60 & .875 \\
\hline & Median & 24.90 & 24.30 & \\
\hline & Minimum & 16.00 & 19.50 & \\
\hline & Maximum & 36.30 & 35.00 & \\
\hline & SD & 6.87 & 5.07 & \\
\hline
\end{tabular}

sum (Mann-Whitney) test statistic, and Spearman's rank correlation coefficient (36). Stepwise multiple regression was used to detect those characteristics most strongly related to intimal size. All $P$ values reflect two-sided tests.

Most statistical procedures used the mean intima values at each measurement site. However, a two-way analysis of variance model with interaction to determine treatment and site effects used the individual replicate measures and found significant differences in mean intimal values by treatment and among the three sites. The site differences resulted from larger intimal values in the thoracic site than in either the abdominal or iliac sites.

\section{Results}

Probucol treatment and lipoprotein profiles. The lipoprotein profiles of the probucol-treated and control monkeys are shown in Table I. There are no statistically significant differences in their lipid profiles nor in the weights of the animals (data not

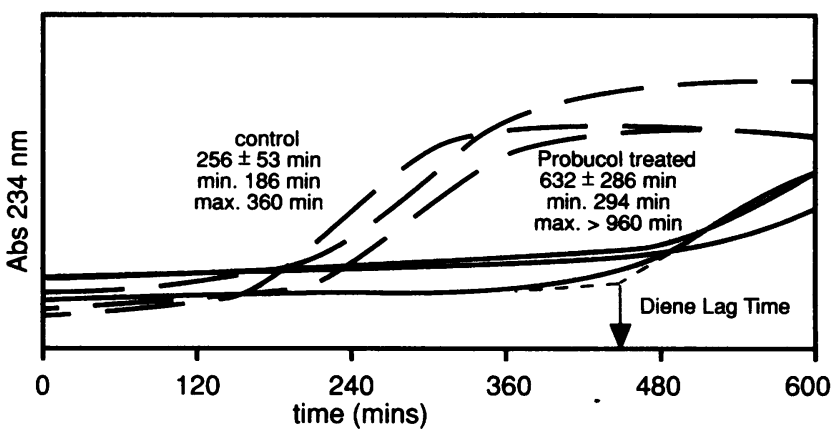

Figure 1. Probucol increases the resistance of plasma LDL to oxidative modification. Time course of conjugated diene formation in plasma LDL isolated from three control (dashed line) and three probucol-treated (solid line) animals are shown, as well as the means and standard deviations for all of the animals in each group. Oxidation of LDL, isolated as described in Methods, was initiated by addition of $\mathrm{CuSO}_{4}$ ( $1.66 \mu \mathrm{M}$ final concentration) and absorbance at $234 \mathrm{~nm}$ was monitored continuously for $10 \mathrm{~h}$. As indicated in the figure, the diene lag time is determined from the intercept of the line defining the baseline and the tangent of the propagation phase as described by Esterbauer et al. (36). Four control and four probucol-treated animals had their diene lag times measured at two separate times and the variation between those measurements averaged $<4 \%$.

shown). Although there are no statistically significant differences in the lipoprotein profiles of the two groups, there was greater variability in the probucol-treated group in the total cholesterol and LDL levels. Median $\mathrm{HDL}_{2}$ levels are lower on average in the probucol-treated animals than in the control animals (median 4.5 versus $9 \mathrm{mg} / \mathrm{dl}$ ). The maximal $P$ value is 0.04 , but a $P$ value of $0.05 / 7=.007$ would be required for statistical significance adjusting for multiple testing.

Probucol increases resistance of plasma $L D L$ to oxidation. To evaluate the effect of probucol on LDL oxidation, plasma LDL was isolated from both the probucol-treated and the control animals, and the lag time for diene formation was determined after initiation of oxidation with copper. Representative profiles of diene formation for three probucol and three control animals are shown in Fig. 1. The mean diene lag times for the eight control animals used for lesion quantitation (also indicated in Fig. 1) is $256 \pm 53 \mathrm{~min}$, whereas the eight probucol-treated animals show significant prolongation of their diene lag times with a mean value of $632 \pm 286 \min (P=.0016)$. The propagation stage of LDL oxidation was not reached even after $960 \mathrm{~min}$ in samples from three of the animals in the probucol group. Therefore, precise lag times could not be determined and are expressed as "greater than 960 min." There is greater variability in the range of diene lag times of oxidation in the probucoltreated animals. In particular, two of the probucol-treated animals differ from the rest in that their lag times of conjugated diene formation (294 and $330 \mathrm{~min}$ ) are comparable with those of the control animals (256 $\pm 53 \mathrm{~min}$, minimum 186 and maximum $360 \mathrm{~min}$ ). However, the plasma probucol levels in these two animals with diene lag times more comparable to control animals are not significantly different from the other probucoltreated animals (data not shown).

Arterial wall, but not plasma, LDL degradation rates are reduced in probucol-treated animals. Tyramine-cellobiose-labeled LDL was injected into four control and four probucol- 


\begin{tabular}{|c|c|c|c|c|c|c|}
\hline \multirow[b]{2}{*}{ Treatment group (animal number) } & \multirow{3}{*}{$\frac{\text { Diene lag time }}{\min }$} & \multirow[b]{2}{*}{ Plasma FCR } & \multicolumn{4}{|c|}{ Arterial FCR } \\
\hline & & & Thoracic aorta & $\begin{array}{l}\text { Abdominal } \\
\text { aorta }\end{array}$ & nliac artery & All sites \\
\hline & & plasma pools/d & \multicolumn{4}{|c|}{ plasma pools/g/d $\times 10^{5}$} \\
\hline \multicolumn{7}{|l|}{ Control } \\
\hline (F87247) & 288 & 0.389 & $\begin{array}{r}13.3 \pm 1.66 \\
(n=11)\end{array}$ & $\begin{array}{r}11.9 \pm 3.0 \\
(n=9)\end{array}$ & $\begin{array}{r}10.6 \pm 1.8 \\
(n=4)\end{array}$ & $\begin{array}{c}12.4 \pm 2.6 \\
(n=27)\end{array}$ \\
\hline (J88014) & 230 & 0.536 & $\begin{array}{l}8.7 \pm 2.42 \\
(n=12)\end{array}$ & $\begin{array}{l}9.0 \pm 2.4 \\
(n=9)\end{array}$ & $\begin{array}{l}8.5 \pm 1.0 \\
(n=4)\end{array}$ & $\begin{array}{l}9.3 \pm 2.69 \\
(n=29)\end{array}$ \\
\hline (J88126) & 360 & 0.627 & $\begin{array}{c}16.1 \pm 2.94 \\
(n=6)\end{array}$ & $\begin{array}{c}12.8 \pm 2.83 \\
(n=8)\end{array}$ & $\begin{array}{l}9.5 \pm 1.21 \\
(n=3)\end{array}$ & $\begin{array}{r}13.9 \pm 3.92 \\
(n=19)\end{array}$ \\
\hline (M86248) & 278 & 0.373 & $\begin{array}{l}9.4 \pm 1.13 \\
(n=8)\end{array}$ & $\begin{array}{l}7.7 \pm 1.22 \\
(n=6)\end{array}$ & $\begin{array}{l}8.3 \pm 2.0 \\
(n=4)\end{array}$ & $\begin{array}{l}8.5 \pm 1.34 \\
(n=20)\end{array}$ \\
\hline Mean \pm SD & & $0.481 \pm 0.122$ & $\begin{array}{r}11.9 \pm 3.4 \\
(n=4)\end{array}$ & $\begin{array}{r}10.4 \pm 2.4 \\
(n=4)\end{array}$ & $\begin{array}{l}9.2 \pm 1.0 \\
(n=4)\end{array}$ & $\begin{array}{r}11.0 \pm 2.6 \\
(n=4)\end{array}$ \\
\hline \multicolumn{7}{|l|}{ Probucol } \\
\hline (F86375) & 478 & 0.348 & $\begin{array}{l}6.9 \pm 1.06 \\
(n=7)\end{array}$ & $\begin{array}{l}7.3 \pm 0.79 \\
(n=7)\end{array}$ & $\begin{array}{l}5.1 \pm 0.78 \\
(n=5)\end{array}$ & $\begin{array}{l}6.5 \pm 1.17 \\
(n=22)\end{array}$ \\
\hline (J87156) & 577 & 0.588 & $\begin{array}{l}2.9 \pm 0.0098 \\
(n=6)\end{array}$ & $\begin{array}{l}3.6 \pm 0.73 \\
(n=6)\end{array}$ & $\begin{array}{c}2.25 \pm 0.26 \\
(n=4)\end{array}$ & $\begin{array}{l}3.0 \pm 0.72 \\
(n=18)\end{array}$ \\
\hline (M86183) & 330 & 0.413 & $\begin{array}{l}8.6 \pm 1.8 \\
(n=9)\end{array}$ & $\begin{array}{l}8.3 \pm 0.79 \\
(n=7)\end{array}$ & $\begin{array}{l}7.0 \pm 1.12 \\
(n=4)\end{array}$ & $\begin{array}{l}8.6 \pm 2.01 \\
(n=23)\end{array}$ \\
\hline (T86327) & $>960$ & 0.468 & $\begin{array}{l}4.4 \pm 0.40 \\
(n=7)\end{array}$ & $\begin{array}{l}5.2 \pm 1.7 \\
(n=6)\end{array}$ & $\begin{array}{l}5.3 \pm 1.0 \\
(n=4)\end{array}$ & $\begin{array}{l}5.0 \pm 1.13 \\
(n=19)\end{array}$ \\
\hline Mean $\pm S D$ & & $0.454 \pm 0.102$ & $\begin{array}{l}5.7 \pm 2.6 \\
(n=4)\end{array}$ & $\begin{array}{l}6.1 \pm 2.2 \\
(n=4)\end{array}$ & $\begin{array}{l}4.9 \pm 2.0 \\
(n=4)\end{array}$ & $\begin{array}{l}5.8 \pm 2.4 \\
(n=4)\end{array}$ \\
\hline$P$ value & & & 0.028 & 0.037 & 0.0084 & 0.0235 \\
\hline
\end{tabular}

treated monkeys to determine the rates of degradation of LDL in arterial lesions. The overall fractional catabolic rate of LDL (plasma FCR) was determined from the disappearance of the radiolabel from the plasma. This indicator of the whole body LDL catabolic rate does not differ significantly between the control and probucol-treated animals (Table II). However, LDL degradation rates measured in arterial segments are significantly different between the two groups. As seen at each of the three sites examined and for all sites combined (Table II), lesions show 40-50\% lower LDL degradation rates in the probucoltreated animals than lesions of the untreated controls. Among the probucol-treated animals was a single monkey (M86183) with a shorter lag time (330 $\mathrm{min})$ for diene formation, more comparable to those of control animals. The degradation rates measured in arterial segments from this animal were also more like the control animals than the three other probucol-treated animals.

Lesions in the probucol-treated monkeys are less mature than those in control animals. Representative lesions from the same segments of the thoracic aorta of the control and probucoltreated animals are shown in Fig. 2, $A$ and $B$, respectively. Thin sections from all of the anatomic sites were obtained from three animals in each treatment group and were examined for lesion morphology. Table III shows the lag time for diene formation and plasma cholesterol and probucol levels for these animals. The intermediate or fibrofatty lesion from one of the probucoltreated monkeys (Fig. $2 \mathrm{~B}$ ) has an early, poorly developed fibrous cap, appears less mature, somewhat thinner, and contains less connective tissue than a lesion from the same anatomic site in a control animal. The lesion from the control animal (Fig. 2 $A$ ) appears to be a more developed fibrous plaque with a well formed fibrous cap, an underlying necrotic core, and calcification. Similar differences were seen in multiple lesions between the two groups of animals at all anatomic levels. Most of the lipid in the lesions from the control animals appears to be localized in the macrophage-rich cores of the advanced lesions that are surrounded by smooth muscle cells. These lipid-filled cores are much less extensive in the probucol-treated animals. In contrast to the controls, there are relatively large numbers of foam cells, which, consist principally of lipid-filled smooth muscle, rather than macrophages. A quantitative analysis of the cellular makeup of these different lesions will be presented in a subsequent manuscript (Chang M., M. Sasahara, A. Chait, P. Wahl, E. W. Raines, and R. Ross, manuscript in preparation).

Marked differences are also observed in the appearance of the smooth muscle cells in the innermost layers of the media in the probucol-treated animals (Fig. 2). At higher magnification, many of the smooth muscle cells within the media immediately beneath the lesions in the probucol-treated animals are heavily lipid laden and contain blue-staining lipid in contrast to cells with white-appearing lipid (due to lipid extraction), which are identified as macrophages (Fig. $2 \mathrm{D}$ ). In comparison, lipid is rarely observed in smooth muscle cells in the lesions or in the media beneath the lesions in the control animals (Fig. $2 C$ ).

Comparison of intimal lesion areas with other parameters. Lesion areas were determined by image analysis of 16 sites in 

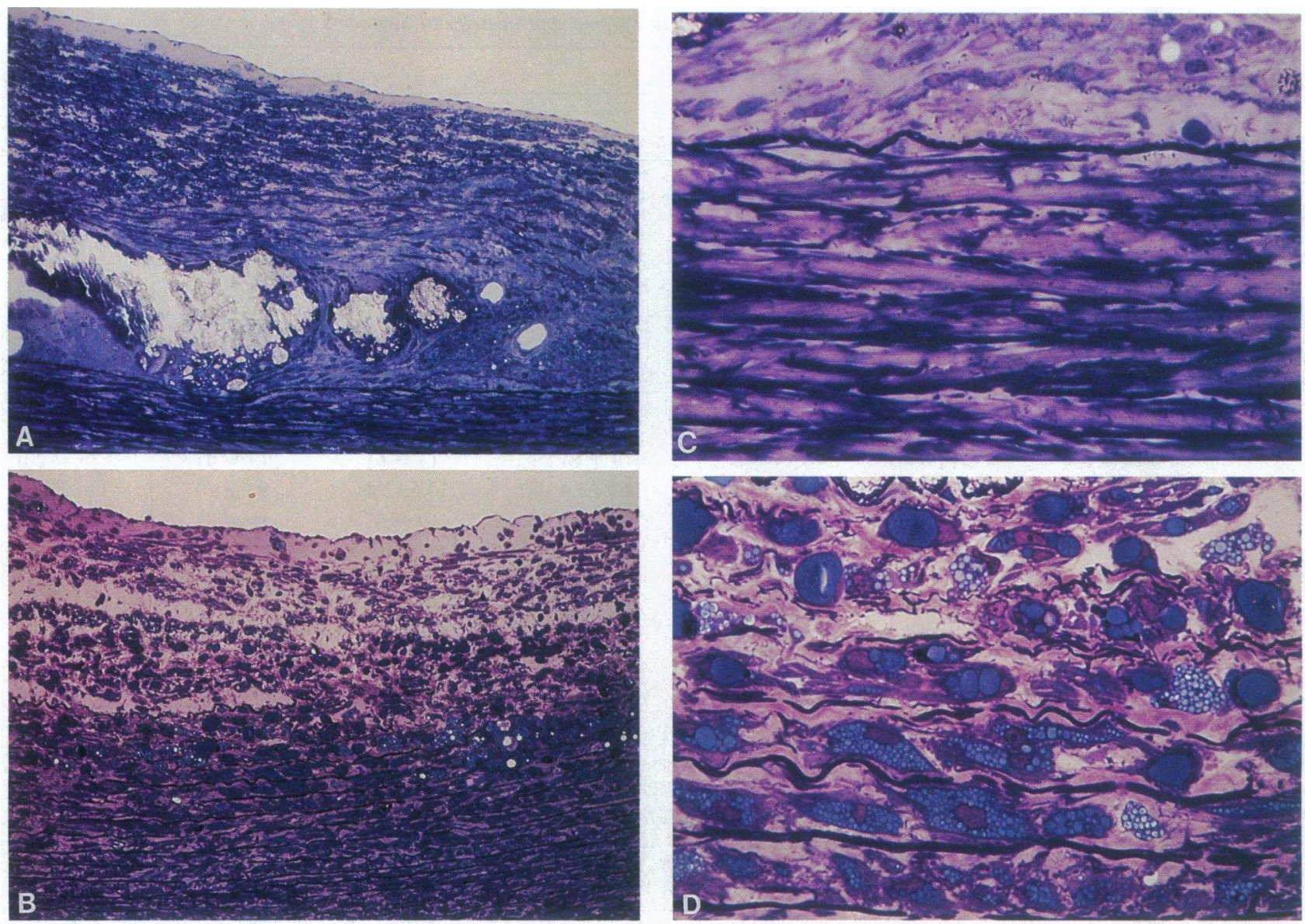

Figure 2. Probucol alters the cellular distribution of lipid within the lesions. Representative sections from the thoracic aorta of a control $(A$ and $C)$ and probucol-treated $(B$ and $D)$ animal were stained with basic fuschsin-methylene blue. Although taken from exactly the same region of the thoracic aorta, the fibrofatty lesion from the probucol-treated animal $(B)$ has fewer cells and much less collagen and, thus, appears less mature than the early fibrous plaque with a well-developed fibrous cap containing numerous smooth muscle cells and collagen that cover a necrotic core in the control animal $(A)$. The innermost layers of the media of these lesions are shown at high power $(C$ and $D)$. Lipid is observed rarely in smooth muscle cells in the media immediately beneath the lesions in the control animals $(C)$. However, in the probucol-treated animals $(D)$, many of the smooth muscle cells in the lesion and in the innermost layers of the media appear to be foam cells filled with blue-staining lipid, due to the dye uptake.

each of the animals. The total lesion area is greatest in the thoracic aorta because of the size of the vessel. However, due to the cephalad progression of lesions characteristic of the nonhuman primate, the most advanced lesions were formed earlier in the iliac arteries and abdominal aorta and thus occupy an area only slightly less than that in the thoracic aorta (23-26).

Table III. Animals Used for Histologic Examination Only

\begin{tabular}{lccc}
\hline Treatment group & Diene lag time & Plasma cholesterol & Plasma probucol \\
\hline \multirow{4}{*}{ Probucol } & $\min$ & $m g / d l$ & $\mu g / m l$ \\
& 493 & $588 \pm 125$ & 12.6 \\
& 580 & $507 \pm 70$ & 22.1 \\
Control & 879 & $511 \pm 131$ & 8.9 \\
& 217 & $561 \pm 97$ & - \\
& 206 & $502 \pm 96$ & - \\
& 178 & $593 \pm 151$ & - \\
\hline
\end{tabular}

After 11 mos on the diet, advanced lesions can be observed throughout the arterial tree, but are more frequent in the iliac arteries and lower abdominal aorta.

When lesion areas were compared between control and probucol groups by treatment, significantly smaller lesion areas are observed in the thoracic aortas of the probucol-treated animals (Fig. 3). However, multiple regression analysis of all 16 animals demonstrates that the intimal lesion areas at all sites are significantly related to oxidation resistance, as measured by the lag time for conjugated diene formation (Table IV). Stepwise multiple regression analysis of lipoprotein profiles and oxidation resistance shows that the size of the lesions in the thoracic aorta correlates inversely with the lag time of oxidation and positively with LDL cholesterol levels. These two variables account for $75 \%$ of the variability in lesion areas observed in the thoracic aorta. Similarly, in the abdominal aorta, the combination of LDL cholesterol and lag time for conjugated diene formation accounts for $59 \%$ of the variability in this region. In contrast, only the oxidation lag time accounts for $39 \%$ of the variability in lesion size in the iliac artery. Therefore, when analyzed in 


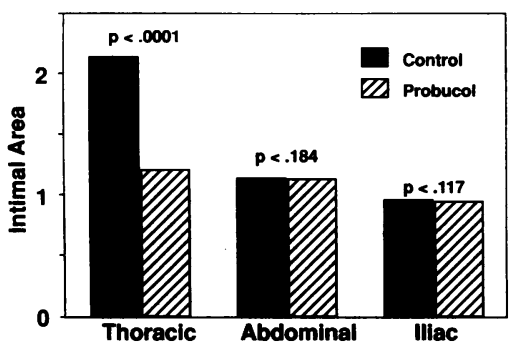

Figure 3. Smaller lesion areas are observed in the thoracic aorta of probucol-treated animals. Lesion areas were determined using an image analysis system for eight control and eight probucol-treated animals and the intimal areas were analyzed for treatment differences within each site using a nonparametric Wilcoxon Rank Sum test (Mann-Whitney). For each monkey, the thoracic and abdominal values are the mean of six sections each from identical anatomical segments, and the iliac value is the mean of four.

this manner, there is a correlation with resistance of LDL to oxidative modification at all three anatomic sites.

Due to the strong correlation of intimal area with resistance of LDL to oxidative modification, lesion area in each of the anatomic regions was plotted against lag time for diene formation (Fig. 4). The data at all sites indicate the striking trend to smaller intimal lesion size associated with increased resistance of plasma LDL to oxidative modification.

\section{Discussion}

Probucol treatment markedly decreases lesion area in the thoracic aorta, the site of early lesions when probucol administration is initiated. The similarity in morphologic appearance of the lesions in $M$. nemestrina with those found in humans and the cephalad progression of the lesions represent important, reproducible components of this study. Upon inducing hypercholesterolemia in these animals, fatty streaks first appear in the iliac arteries, then in the abdominal aorta, subsequently in the thoracic aorta, and finally in the coronary arteries. With increasing time on the diet, the lesions at each site progress to fibrofatty lesions and ultimately to fibrous plaques. Thus, taking advantage of the temporal sequence of the cephalad progression of lesions characteristic of the nonhuman primate provides an opportunity to determine whether antioxidant therapy alters the initiation and/or progression of the lesions of atherosclerosis.

Probucol was started after the monkeys had been on the diet for $3.5 \mathrm{mos}$, by which time early fatty streaks are present in the

Table IV. Stepwise Regression Analysis of Variables Related to Intima Values

\begin{tabular}{llll}
\hline & \multicolumn{1}{c}{ Variables } & $P$ value & R squared \\
\hline \multirow{3}{*}{ Thoracic } & & & $\%$ \\
& Diene lag & .0014 & 55.7 \\
& Diene lag & .0003 & 74.5 \\
Abdominal & + LDL & .0114 & \\
& LDL & .032 & 30.7 \\
& LDL2 & .0085 & 59.1 \\
Iliac (log) & + Diene lag & .0136 & \\
& Diene lag & .0122 & 39.4 \\
\hline
\end{tabular}

thoracic and upper abdominal aorta, whereas more advanced, fibrofatty lesions are already present in the iliac arteries. Analysis of the lesions after an additional 7.5 mos of hypercholesterolemia demonstrated the greatest reduction in intimal areas and most statistically significant differences in this study in the thoracic aorta. Since either no lesions or early fatty streaks were present at that anatomic site when probucol treatment was initiated, it was possible to study its effect at an early stage and throughout lesion development. These observations suggest that probucol may beneficially affect the cellular changes that take place during the early phases of atherogenesis to a greater extent than those associated with more advanced lesions. Observations in the WHHL rabbit are also consistent with a greater effect on earlier lesions of atherosclerosis (37). Initiation of probucol treatment at 2 mos reduced lesion size by $75 \%$ while starting probucol therapy at 8 mos decreased lesion size by $54 \%$. Together, these data suggest that the efficacy of probucol in altering lesion formation at early stages as compared with more advanced lesions warrants further analysis.

Resistance of plasma LDL to oxidation strongly correlates with a reduction in lesion size. Bivariate analysis of our data demonstrates that the intimal areas are significantly related to resistance of LDL to oxidation at all sites (thoracic, abdominal, and iliac arteries). Our data also clearly show very significant decreases in the intimal area in the thoracic aorta of the probucol-treated animals. However, our inability to observe statistically significant differences in other anatomic sites may be due to the small number of monkeys $(n=16)$. In spite of using small sample statistical techniques, we have $<30 \%$ statistical power to detect differences between the control and probucoltreated monkeys. Ideally, one would like $80-90 \%$ statistical power. Thus, there may be other differences between the two groups that we are unable to detect statistically with this relatively small sample. Beyond the data provided in our study, the significance of antioxidant therapy is supported by the fact that other antioxidant compounds, some with properties very different from probucol (e.g., butylated hydroxytoluene, N, N'-diphenyl-phenylenediamine and vitamin $\mathrm{E}$ ), are also anti-atherogenic in other animal models $(18,21,22)$. However, the issue of whether resistance of plasma LDL to oxidation measured in vitro will be predictive of in vivo changes requires further examination of larger numbers of animals.

The cholesterol-lowering effects of probucol were normalized in the controls by adjusting their dietary intake. Probucol decreases total plasma cholesterol in humans $(38,39)$ and in most animal species that have been tested, including nonhuman primates. The magnitude of the effect varies considerably from species to species, but in most instances both LDL and HDL cholesterol levels decrease. This poses a problem in attempting to dissociate the effects of probucol as an antioxidant from its effect as a cholesterol-lowering agent. In the present studies, this problem was approached by lowering the cholesterol content of the diet in the control group so that their plasma cholesterol levels would match the levels observed in the probucol-treated group, a $\sim 22 \%(n=11)$ decrease in total plasma cholesterol ( $19 \%$ in LDL and $5.0 \%$ in HDL). With this adjustment in dietary cholesterol intake, there were no significant differences between control and probucol-treated animals in the levels of total cholesterol, LDL cholesterol or HDL cholesterol.

LDL particle structure, and its possible alteration by probucol, was not analyzed in this study. However, in humans, probu- 


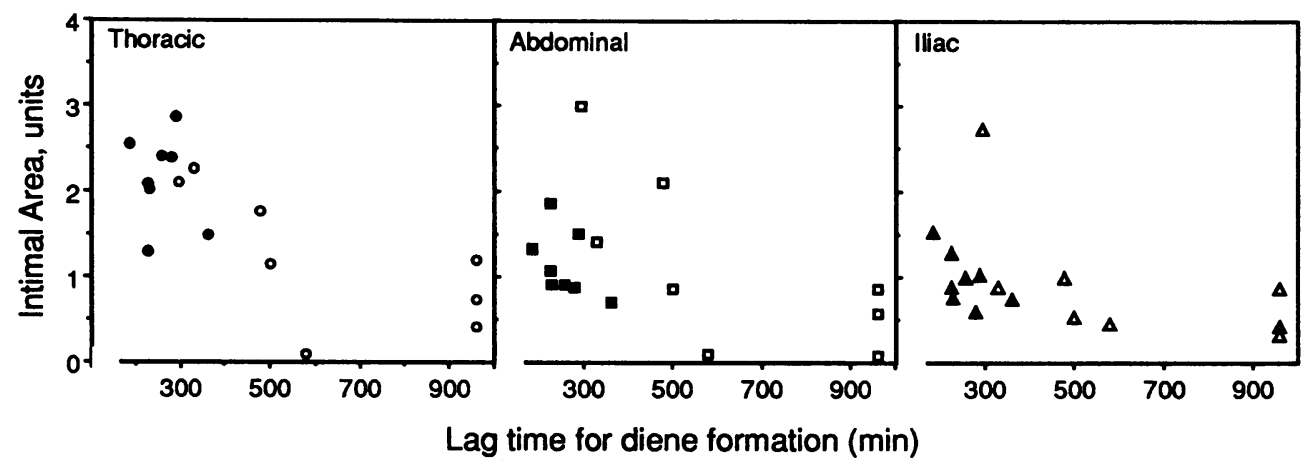

Figure 4. A trend toward inverse correlation of intimal areas with resistance of plasma LDL to oxidative modification is observed at all sites. The mean intimal area for each animal (control, closed symbols; probucol, open symbols) is plotted versus the lag time of oxidation for each of the three measurement sites. A strong trend toward an inverse relationship between intimal lesion size and oxidation resistance is observed in the thoracic and abdominal aorta and in the iliac arteries. col has been shown to deplete cholesterol esters relative to protein (40), which would result in small, dense LDL. This small, dense LDL would actually be more susceptible to oxidation (41), and, therefore, possibly enhance lesion formation, in contrast to its antioxidant properties.

Probucol increases resistance of plasma $L D L$ to oxidative modification and decreases $L D L$ degradation in lesion areas. Comparable with its effect in humans $(42,43)$, probucol administration effectively increases the resistance of plasma LDL from $M$. nemestrina to in vitro copper-induced oxidation. Although their plasma probucol levels were not significantly different from the others, 2 of the 8 probucol-treated monkeys demonstrated a decreased efficacy of probucol treatment as measured by lag time for conjugated diene formation, and, in 1 of 4 animals, in vivo degradation of LDL measured in arterial sections more closely resembled control animals. Studies in humans have demonstrated a similar variability in response to probucol and, in some cases, a correlation between increased resistance of LDL to oxidation and content of probucol in LDL (43). Probucol content of LDL was not determined in this study. Resistance of LDL to oxidation is determined by many variables, including fatty acid composition, endogenous antioxidant content, and lipoprotein size and density. It should be noted that even with the inclusion of these two probucol-treated animals with diene lag times more comparable to control animals, there was a highly significant inhibition of lesion formation in the thoracic aorta of the probucol-treated group.

The plasma and lesion degradation of LDL was determined by injection of tyramine-cellobiose-labeled LDL. As previously observed in probucol treatment of the WHHL rabbit (15), probucol has no effect on the plasma fractional catabolic rate of LDL degradation, whereas the lesions in the probucoltreated monkeys have $40-50 \%$ lower LDL degradation rates compared with those in the controls. Uptake of native LDL by macrophages in vitro is very slow (6), and foam cells in fatty streak lesions express very few native LDL receptors but a large number of acetyl LDL receptors (44). Therefore, it is reasonable to infer that degradation in lesions occurs mainly after conversion of native LDL to the oxidatively modified form, and thus, to a ligand for the scavenger receptor. This was the interpretation offered by Carew et al. (15) for the similar probucol effect they observed in LDL receptor-deficient rabbits. However, the decreased LDL degradation in lesion areas of the probucol-treated group may reflect the smaller and less cellular lesions observed in these animals (Fig. 2; Chang M., M. Sasa- hara, A. Chait, P. Wahl, E. W. Raines, and R. Ross, manuscript in preparation ) or, alternatively, the prolonged effect of $6.5 \mathrm{mos}$ of antioxidant therapy.

How does probucol affect the evolution of atherosclerotic lesions? An unexpected finding in the probucol-treated animals is increased accumulation of lipid in both lesion smooth muscle cells and in medial smooth muscle cells immediately beneath the lesions. This may reflect a decrease in the number of macrophages present, and thus, able to take up the lipoproteins, or a decreased uptake of plasma LDL by lesion macrophages, or both. This difference may also be related to the lower $\mathrm{HDL}_{2}$ levels in the probucol-treated animals. We are currently analyzing the cellular and molecular composition of the lesions in the probucol-treated versus the control monkeys, including immunolocalization of both native and oxidized LDL (Chang M., M. Sashara, A. Chait, P. Wahl, E. W. Raines, and R. Ross, manuscript in preparation). Qualitative analyses in WHHL rabbits showed that macrophages were more prevalent in the lesions of the control animals, as compared with the lesions in the probucol-treated animals, in which smooth muscle cells appeared to predominate (45). Interestingly, evaluation of a limited number of probucol-treated familial hypercholesterolemic patients noted nonmacrophage-related accumulation of cholesterol, in spite of reduction in cholesterol levels and regression of xanthomas (46). These observations, together with ours in the nonhuman primate, suggest that probucol may alter the distribution of cholesterol from the macrophage to other cells, possibly smooth muscle in the nonhuman primates.

Additionally, beyond its antioxidant activity, probucol has several biological properties that might contribute to its antiatherogenic potential. First, it can influence lipoprotein levels. We attempted to negate this effect in the present study by maintaining the LDL cholesterol levels in the two groups at similar levels by adjusting cholesterol intake. HDL levels were lower in the probucol-treated animals, as in other species (38-40). However, this would be expected to enhance, rather than inhibit, atherogenesis. Probucol can also induce cholesterol ester transfer protein (47); can inhibit the release of the cytokine, interleukin-1, from peritoneal macrophages of probucol-treated mice (48); and can exert an intracellular effect on the ability of cells to oxidize LDL (49). The importance of these effects, demonstrated in cell culture systems, has yet to be evaluated in vivo. However, the possibility that one or more of these activities contributes to the protective effect of probucol, in addition to its antioxidant properties, cannot be eliminated in the present study. 
Understanding the cellular and molecular mechanisms responsible for decreased lesion size is key to evaluating the efficacy of antioxidant therapy and its possible roles in inhibiting initiation and/or progression of lesions of atherosclerosis. Qualitative observations in probucol-treated WHHL rabbits that macrophages predominate in lesions of control animals as compared with more smooth muscle cell-rich lesions in the probucol-treated rabbits (45) are consistent with a decrease in oxidized LDL and a consequent decreased recruitment and retention of monocytes in the lesions (50). To examine the cellular and molecular differences in the intimal lesions in the probucoltreated versus the control animals, both quantitative and qualitative immunohistochemical analyses are being performed on arterial samples obtained from this study (Chang M., M. Sasahara, R. Chait, P. Wahl, E. W. Raines, and R. Ross, manuscript in preparation). Such a comparison of the cellular and molecular composition of the lesions at the different anatomic sites should help to further define the effects of probucol and other antioxidant therapy on lesion initiation versus lesion progression.

\section{Acknowledgments}

We acknowledge the excellent technical assistance of Jon Dickey, Karen Engel, and Li-Chuan Huang, and the editorial assistance in preparation of the manuscript of Barbara Droker.

These studies were supported by National Institutes of Health grants HL-18645 (to R. Ross, E. W. Raines, and A. Chait), HL-14197 (to T. E. Carew and D. Steinberg), RR-00166 to the Regional Primate Research Center, and an unrestricted grant for cardiovascular research from Bristol-Myers Squibb Company (to R. Ross).

\section{References}

1. Ross, R. 1986. The pathogenesis of atherosclerosis-an update. N. Engl. J. Med. 314:488-500.

2. Ross, R. 1993. The pathogenesis of atherosclerosis: a perspective for the 1990s. Nature (Lond.). 362:801-809.

3. von Rokitansky, C. 1855. A Manual of Pathological Anatomy (translated by G. E. Day). Vol. 4 . The Sydenham Society, London.

4. Virchow, R. 1856. Phlogose ung thrombose im gefassystem. In Gesammelte Abhandlungen zur Wissenschaftlichen Medicin. Meidinger Sohn and Co., Berlin. 458-463.

5. Barth, J. D., and A. C. Arntzenius. 1991. Progression and regression of atherosclerosis, what roles for LDL-cholesterol and HDL-cholesterol: a perspective. Eur. Heart J. 12:952-957.

6. Brown, M. S., and J. L. Goldstein. 1983. Lipoprotein metabolism in the macrophage: implications for cholesterol deposition in atherosclerosis. Annu. Rev. Biochem. 52:223-261.

7. Kodama, T., M. Freeman, L. Rohrer, J. Zabrecky, P. Matsudaira, and M. Krieger. 1990. Type I macrophage scavenger receptor contains alpha-helical and collagen-like coiled coils. Nature (Lond.). 343:531-535.

8. Henriksen, T., E. M. Mahoney, and D. Steinberg. 1983. Enhanced macrophage degradation of biological modified low density lipoprotein. Arteriosclerosis. 3:149-159.

9. Steinbrecher, U. P., S. Parthasarathy, D. S. Leake, and J. L. Witztum. 1984. Modification of low density lipoprotein by endothelial cells involves phospholipids. Proc. Natl. Acad. Sci. USA. 81:3883-3887.

10. Morel, D. W., P. E. DiCorleto, and G. M. Chisolm. 1986. Modulation of endotoxin-induced endothelial cell toxicity by low density lipoprotein. Lab. Invest. 55:419-426.

11. Heinicke, J. W., H. Rosen, L. A. Suzuki, and A. Chait. 1987. The role of sulfur-containing amino acids in superoxide production and modification of low density lipoprotein by arterial smooth muscle cells. J. Biol. Chem. 262:1009810103.

12. Steinberg, D., S. Parthasarathy, T. E. Carew, J. C. Khoo, and J. L. Witztum. 1989. Beyond cholesterol: Modifications of low-density lipoprotein that increase its atherogenicity. N. Engl. J. Med. 320:915-924.

13. Witztum, J. L., and D. Steinberg. 1991. Role of oxidized low density lipoprotein in atherogenesis. J. Clin. Invest. 88:1785-1792.

14. Parthasarathy, S., S. G. Young, J. L. Witztum, R. C. Pittman, and D.
Steinberg. 1986. Probucol inhibits oxidative modification of low density lipoprotein. J. Clin. Invest. 77:641-644.

15. Carew, T. E., D. C. Schwenke, and D. Steinberg. 1987. Antiatherogenic effect of probucol unrelated to its hypercholesterolemic effect: evidence that antioxidants in vivo can selectively inhibit low density lipoprotein degradation in macrophage-rich fatty streaks slowing the progression of atherosclerosis in the WHHL rabbit. Proc. Natl. Acad. Sci. USA. 84:7725-7729.

16. Kita, T., Y. Nagano, M. Yokode, K. Ishii, N. Kume, A. Ooshima, H. Yoshida, and C. Kawai. 1987. Probucol prevents the progression of atherosclerosis in Watanabe heritable hyperlipidemic rabbit, an animal model for familial hypercholesterolemia. Proc. Natl. Acad. Sci. USA. 84:5928-5931.

17. Wissler, R. W., and D. Vesselinovitch. 1983. Combined effects of cholestyramine and probucol on regression of atherosclerosis in rhesus monkey aortas. Appl. Pathol. 1:89-96.

18. Verlangieri, A. J., and M. J. Bush. 1992. Effects of d-alpha-tocopherol supplementation on experimentally induced primate atherosclerosis. J. Am. Coll. Nutr. 11:131-138.

19. Daugherty, A., B. S. Zweifel, and G. Schonfeld. 1989. Probucol attenuates the development of aortic atherosclerosis in cholesterol-fed rabbits. Br. J. Pharmacol. 98:612-618.

20. Stein, Y., O. Stein, B. Delplanque, J. D. Fesmire, D. M. Lee, and P. Alaupovic. 1989. Lack of effect of probucol on atheroma formation in cholesterolfed rabbits kept at comparable plasma cholesterol levels. Atherosclerosis. 75:145155.

21. Bjorkhem, I., A. H. Henriksson-Freyschuss, O. Breuer, U. Diczfalusy, L. Berglund, and P. Henriksson. 1991. The antioxidant butylated hydroxytoluene protects against atherosclerosis. Arterioscler. Thromb. 11:15-22.

22. Sparrow, C. P., T. W. Doebber, J. Olaszewski, M. S. Wu, J. Ventre, K. A., Stevens, and Y. S. Chao. 1992. Low density lipoprotein is protected from oxidation and the progression of atherosclerosis is slowed in cholesterol-fed rabbits by the antioxidant $\mathrm{N}, \mathrm{N}^{\prime}$-diphenyl-phenylenediamine. J. Clin. Invest. 86:1885-1891.

23. Faggiotto, A., R. Ross, and L. Harker. 1984. Studies of hypercholesterolemia in the nonhuman primate. I. Changes that lead to fatty streak formation. Arteriosclerosis. 4:323-340.

24. Faggiotto, A., and R. Ross. 1984. Studies of hypercholesterolemia in the nonhuman primate. II. Fatty streak conversion to fibrous plaque. Arteriosclerosis. 4:341-356.

25. Masuda, J., and R. Ross. 1990. Atherogenesis during low level hypercholesterolemia in the nonhuman primate. I. Fatty streak formation. Arteriosclerosis. 10:164-177.

26. Masuda, J., and R. Ross. 1990. Atherogenesis during low level hypercholesterolemia in the nonhuman primate. II. Fatty streak conversion to fibrous plaque. Arteriosclerosis. 10:178-187.

27. Buckley, M. M.-T., K. L. Goa, A. H. Price, and R. N. Brogden. 1989. Probucol: a reappraisal of its pharmacological properties and therapeutic use in hypercholesterolaemia. Drugs. 37:761-800.

28. Warnick, G. R. 1986. Enzymatic methods for quantification of lipoprotein lipids. In Methods in Enzymology. Vol. 129. J. J. Albers and J. P. Segrest, editors. Academic Press, Orlando FL. 101-123.

29. Chung, B. H., T. Wilkinson, J. C. Geer, and J. P. Segrest. 1980. Preparative and quantitative isolation of plasma lipoproteins: Rapid, single discontinuous density gradient ultracentrifugation in a vertical rotor. J. Lipid Res. 21:284-291.

30. Esterbauer, H., G. Striegl, H. Puhl, and M. Rotheneder. 1989. Continuous monitoring of in vitro oxidation of human low density lipoprotein. Free Radical Res. Comms. 6:67-75.

31. Havel, R. J., H. A. Eder, and J. H. Bragdon. 1955. The distribution and chemical composition of ultracentrifugally separated lipoproteins in human serum. J. Clin. Invest. 34:1345-1353.

32. Schwenke, D. C., and T. E. Carew. 1989. Initiation of atherosclerotic lesions in cholesterol-fed rabbits. I. Focal increases in arterial LDL concentration precede development of fatty streak lesions. Arteriosclerosis. 9:895-907.

33. Pittman, R. C., T. E. Carew, C. K. Glass, S. R. Green, C. A. Taylor, Jr., and A. D. Attie. 1983. A radioiodinated, intracellularly trapped ligand for determining the tissue sites of plasma protein degradation in vivo. Biochem. J. 212:791-800.

34. Pittman, R. C., and C. A. Taylor. 1986. Methods for assessment of tissue sites of lipoprotein degradation. Methods Enzymol. 129:612-628.

35. Fisher, L., and G. van Belle. 1993. Biostatistics. A Methodology for the Health Sciences. John Wiley and Sons, Inc., New York. 1-991.

36. Neter, J., W. Wasserman, and M. Kutner. 1990. Applied Linear Statistical Models, 3rd edition. Hovewood, IL, Richard D. Irwin, Inc. 406-407.

37. Nagano, Y., T. Nakamura, Y. Matsuzawa, M. Cho, Y. Ueda, and T. Kita. 1992. Probucol and atherosclerosis in the Watanabe heritable hyperlipidemic rabbit-long-term antiatherogenic effect and effects on established plaques. Atherosclerosis. 92:131-140.

38. Sirtori, C. R., M. Sirtori, L. Calabresi, and G. Franceschini. 1988. Changes in high-density lipoprotein subfraction distribution and increased cholesteryl ester transfer after probucol. Am. J. Cardiol. 62:73B-76B. 
39. Wetterau, J. R., K. A. Combs, H. W. Albers, G. Lamkin, E. A. Stein, R. L. Barnhart, E. M. Chi, R. L. Jackson, and J. A. K. Harmony. 1992. Effects of probucol on plasma lipids, lipoproteins and parameters of high density lipoprotein metabolism. Horm. Metab. Res. 24:289-296.

40. Lock, D. R., I. Kuisk, B. Gonen, W. Patsch, and G. Schonfeld. 1983. Effect of probucol on the composition of lipoproteins and on VLDL apoprotein B turnover. Atherosclerosis. 47:271-278.

41. Chait, A., R. L. Brazg, D. L. Tribble, and R. M. Krauss. 1993. Susceptibility of small, dense, low-density lipoproteins to oxidative modification in subjects with the atherogenic lipoprotein phenotype, pattern B. Am. J. Med. 94:350-356.

42. Regnström, J., G. Walldius, L. A. Carson, and J. Nilsson. 1990. Effect of probucol treatment on the susceptibility of low density lipoprotein isolated from hypercholesterolemic patients to become oxidatively modified in vitro. Atherosclerosis. 82:43-51.

43. Reaven, P. D., S. Parthasarathy, W. F. Beltz, and J. L. Witztum. 1992. Effect of probucol dosage on plasma lipid and lipoprotein levels and on protection of low density lipoprotein against in vitro oxidation in humans. Arterioscler. Throm. 12:318-324.

44. Ylä-Herttuala, S., M. E. Rosenfeld, S. Parthasarathy, E. Sigal, T. Särkioja, J. L. Witztum, and D. Steinberg. 1991. Gene expression in macrophage-rich human atherosclerotic lesions: 15-lipoxygenase and acetyl LDL receptor mRNA colocalize with oxidation-specific lipid-protein adducts. J. Clin. Invest. 87:11461152
45. O'Brien, K., Y. Nagano, A. M. Gown, T. Kita, and A. Chait. 1991. Probucol treatment affects the cellular composition but not anti-oxidized low density lipoprotein immunoreactivity of plaques from Watanabe heritable hyperlipidemic rabbits. Arterioscler. Thromb. 11:751-759.

46. Nakamura, T., Y. Ueyama, T. Funahashi, S. Yamashita, K. K. Takemura M. Kubo, K. Yamada, and Y. Matsuzawa. 1992. Non-macrophage-related accumulation of cholesterol during probucol treatment in familial hypercholesterolemia: report of two cases. Atherosclerosis. 92:193-202.

47. Marcel, Y. L., R. McPherson, M. Hogue, H. Czarnecka, Z. Zawadzki, P. K. Weech, M. E. Whitlock, A. R. Tall, and R. W. Milne. 1990. Distribution and concentration of cholesteryl ester transfer protein in plasma of normolipemic subjects. J. Clin. Invest. 85:10-17.

48. Ku, G., N. S. Doherty, J. A. Wolos, and R. L. Jackson. 1988. Inhibition by probucol of interleukin 1 secretion and its implication in atherosclerosis. Am. J. Cardiol. 62:77B-81B.

49. Parthasarathy, S. 1992. Evidence for an additional intracellular site of action of probucol in the prevention of oxidative modification of low density lipoprotein. Use of a new water-soluble probucol derivative. J. Clin. Invest. 89:1618-1621.

50. Quinn, M. T., S. Parthasarathy, L. G. Fong, and D. Steinberg. 1987. Oxidatively modified low density lipoproteins: A potential role in recruitment and retention of monocyte/macrophages during atherogenesis. Proc. Natl. Acad. Sci. USA. 84:2995-2998. 